\title{
A Chlorophyll Fluorescence-based Biofeedback System to Control Photosynthetic Lighting in Controlled Environment Agriculture
}

\author{
Marc W. van Iersel ${ }^{1}$, Geoffrey Weaver, and Michael T. Martin \\ Department of Horticulture, University of Georgia, 1111 Miller Plant Science Building, Athens, GA \\ 30602
}

\author{
Rhuanito S. Ferrarezi \\ Agricultural Experiment Station, University of the Virgin Islands, RRI Box 10,000, Kingshill, VI \\ 00850
}

Erico Mattos

PhytoSynthetix LLC, 111 Riverbend Rd, Athens, GA 30602

Mark Haidekker

College of Engineering, University of Georgia, 597 DW Brooks Drive, Athens, GA 30602

\begin{abstract}
AdDitional INDEX words. duty cycle, electron transport rate, light-emitting diodes, nonphotochemical quenching, photoinhibition, photosynthetic photon flux density, quantum yield of photosystem II

Abstract. Photosynthetic lighting is one of the main costs of running controlled environment agriculture facilities. To optimize photosynthetic lighting, it is important to understand how plants use the provided light. When photosynthetic pigments absorb photons, the energy from those photons is used to drive the light reactions of photosynthesis, thermally dissipated, or re-emitted by chlorophyll as fluorescence. Chlorophyll fluorescence measurements can be used to determine the quantum yield of photosystem II ( $\left.\Phi_{\text {PSII }}\right)$ and nonphotochemical quenching (NPQ), which is indicative of the amount of absorbed light energy that is dissipated as heat. Our objective was to develop and test a biofeedback system that allows for the control of photosynthetic photon flux density (PPFD) based on the physiological performance of the plants. To do so, we used a chlorophyll fluorometer to measure $\Phi_{\text {PSII, }}$ and used these data and PPFD to calculate the electron transport rate (ETR) through PSII. A datalogger then adjusted the duty cycle of the light-emitting diodes (LEDs) based on the ratio of the measured ETR to a predefined

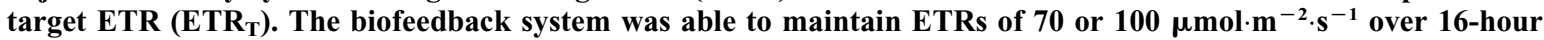
periods in experiments conducted with lettuce (Lactuca sativa). With an $\mathbf{E T R}_{\mathrm{T}}$ of $70 \mu \mathrm{mol} \cdot \mathrm{m}^{-2} \cdot \mathrm{s}^{-1}, \Phi_{\mathrm{PSII}}$ was stable throughout the 16 hour and no appreciable changes in $P P F D$ were needed. At an $E T R_{T}$ of $100 \mu \mathrm{mol} \cdot \mathrm{m}^{-2} \cdot \mathrm{s}^{-1}, \Phi_{\mathrm{PSII}}$ gradually decreased from 0.612 to 0.582 . To maintain ETR at $100 \mu \mathrm{mol} \cdot \mathrm{m}^{-2} \cdot \mathrm{s}^{-1}, P P F D$ had to be increased from 389 to $409 \mu \mathrm{mol} \cdot \mathrm{m}^{-2} \cdot \mathrm{s}^{-1}$, resulting in a gradual decrease of $\Phi_{P S I}$ and an increase in NPQ. The ability of the biofeedback system to achieve a range of different ETRs within a single day was tested using lettuce, sweetpotato (Ipomoea batatas), and pothos (Epipremnum aureum). As the $\mathrm{ETR}_{\mathrm{T}}$ was gradually increased, the $P P F D$ required to achieve that ETR also increased, whereas $\Phi_{P S I}$ decreased. Surprisingly, a subsequent decrease in $E T R_{T}$, and in the $P P F D$ required to

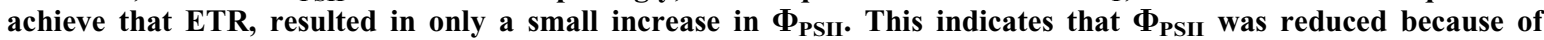
photoinhibition. Our results show that the biofeedback system is able to maintain a wide range of ETRs, while it also is capable of distinguishing between NPQ and photoinhibition as causes for decreases in $\Phi_{\text {PSII }}$.
\end{abstract}

Controlled environment agriculture, including greenhouses and indoor production facilities, is becoming an increasingly important part of the global food system. Totally enclosed, indoor vegetable growing facilities were developed in Japan beginning in the 1970s. These "plant factories" and similar operations can now be found in or near major cities across the world (Despommier, 2013; Goto, 2012; Liu, 2012; Mok et al., 2014; Thomaier et al., 2015). Recently, there has been much interest in the potential of large-scale, indoor agricultural production, often referred to as vertical farming. Vertical farming has been heralded as a potential solution to feeding

Received for publication 19 Nov. 2015. Accepted for publication 31 Dec. 2015. Funding for this research was provided by the Georgia Research Alliance, USDA-NIFA-SBIR award 2015-33610-23472, and the Fred C. Gloeckner Foundation.

${ }^{1}$ Corresponding author. E-mail: mvanier@uga.edu. a rapidly growing population while minimizing the environmental impacts of crop production (Despommier, 2010). It is estimated that vertical farms could produce 200 to $1000 \times$ more food per unit land area than traditional agriculture (Germer et al., 2011; Zeidler et al., 2013). However, building and operating vertical farms is expensive and edible biomass produced in a vertical farm would need to be sold for $\approx \$ 13.75 / \mathrm{kg}$ to cover the cost of operations (Zeidler et al., 2013).

The feasibility and sustainability of large-scale plant factories are questionable. Plant factories are expensive to operate, partly because of the large power requirements of electric lamps that provide the actinic light that drives the light reactions of photosynthesis. In enclosed plant factories, photosynthesis is driven exclusively by electric light, and sunlight can at best provide a small percentage of the light required by vertical farms (Germer et al., 2011; Goto, 2012; Mok et al., 2014; Watanabe, 2011). Light-emitting diodes (LEDs) have become a popular 
light source for indoor vegetable cultivation because they are considered to be energy efficient (Bourget, 2008; Goto, 2012; Liu, 2012; Morrow, 2008; Yeh and Chung, 2009), although the actual efficiency is debated. Nelson and Bugbee (2014) found that the efficiency of LED lights is similar to that of good highpressure sodium lights. In contrast, Ouzounis et al. (2015) state that good LED lights are more efficient than high-pressure sodium lights. Ouzounis et al. (2015) also conclude that the payback time for LEDs is now realistic, although this depends on electricity pricing. Furthermore, they point out that LEDs have unique properties that can make them more cost-effective, such as the ability to control light intensity and spectra. In a conceptual cost analysis of building and operating a large vertical farm, it was shown that the greatest recurring cost would be electricity. Powering and cooling LED lights would account for more than $30 \%$ of the operation's total electrical cost (Zeidler et al., 2013). In plant factories, lighting accounts for $\approx 40 \%$ of the total recurring costs (Watanabe, 2011).

The overall efficiency of converting electric light energy into biomass is complicated by the nature of the light reactions of photosynthesis. Not all photons absorbed by chlorophyll and accessory pigments are used to drive the light reactions. Excess absorbed photons can cause damage within the chloroplast. The reaction center of PSII, particularly the D1 protein, is highly susceptible to light-induced damage (photoinhibition), which decreases quantum yield of PSII. Higher plants have developed a complex set of responses to excess light, which allows them to safely dissipate excess light energy as heat (resulting in NPQ) and minimize photoinhibition (Demmig-Adams et al., 2012; Dietz, 2015; Horton, 2012; Rochaix, 2014).

Although most of the light energy absorbed in chloroplasts is either used to drive photosynthesis or is thermally dissipated, a small fraction is re-emitted by chlorophyll as fluorescence. Chlorophyll fluorescence measurements can be used to quickly and reliably determine $\Phi_{\text {PSII }}$ (Maxwell and Johnson, 2000). Generally, a decrease in $\Phi_{\text {PSII }}$ indicates that either plants dissipate an increasing fraction of the absorbed light energy as heat (an upregulation of NPQ) or photoinhibition has occurred. Chlorophyll fluorescence measurements can be used to quantify NPQ, based on changes in light-saturated fluorescence under actinic light. Combined with $P P F D, \Phi_{\text {PSII }}$ can be used to estimate electron transport rate through PSII (Baker and Rosenqvist, 2004; Genty et al., 1989). Because chlorophyll fluorescence is relatively easy to measure and provides detailed physiological information, such measurements can be a valuable tool to optimize greenhouse production (Baker and Rosenqvist, 2004) and to monitor crop responses to light (Pocock, 2015). For example, Janka et al. (2015) used chlorophyll fluorescence measurements to monitor diurnal and dynamic fluctuations in $\Phi_{\text {PSII }}$ of greenhouse crops. Our objective was to develop a biofeedback system that not only monitors $\Phi_{\text {PSII }}$ and ETR, but that can also control the $P P F D$ from LED lights to maintain a specific ETR. Controlling the intensity of actinic light based on plants' ability to use it efficiently may substantially reduce the energy cost of LED lighting, and contribute to making large-scale controlled environment agriculture more profitable.

\section{Materials and Methods}

LEDs AND CONTROL SYSTEM. Photosynthetic light was provided using a custom-built 400-W LED array consisting of four 100-W warm-white LED modules (3000 K; EpiLEDs, Tainan,
Taiwan) mounted on aluminum heat sinks with air circulation provided by two 120 -mm cooling fans. Glass lenses (Satistronix Group, Shenzhen, China) were attached below the LED modules to focus the light on the plant production area below the LEDs. The lights were powered using a $30-\mathrm{V}$ DC power supply (Fig. 1). The LED array lighted an area of $\approx 0.75 \mathrm{~m}^{2}$.

A custom-made control board was used to alter the duty cycle of the LEDs (Fig. 1). The LEDs were continuously turned on and off (at $\approx 1000 \mathrm{~Hz}$ in this study; i.e., each on/off cycle lasted $1 \mathrm{~ms}$ ) and duty cycle is the proportion of time that the diodes are energized during each cycle. Thus, the intensity of the LED light was modified by changing the duty cycle. The control board altered the duty cycle of the LEDs proportionally in response to an external 0 - to $2-\mathrm{V}$ DC signal supplied to the board. To provide this voltage signal, an analog output module (SDM-A04; Campbell Scientific, Logan, UT) was connected to a datalogger (CR1000; Campbell Scientific).

Chlorophyll Fluorescence measurements. Chlorophyll fluorescence was measured with a pulse-amplitude modulated fluorometer (MINI-PAM; Heinz Walz, Effeltrich, Germany). The fluorometer provided an analog voltage signal to the datalogger, proportional to the measured fluorescence. Following measurements of steady-state fluorescence $\left(\mathrm{F}_{0}\right.$ and $\mathrm{F}_{\mathrm{s}}$ in the dark and light, respectively), the datalogger sent a serial signal to the fluorometer to trigger a saturating light pulse and then
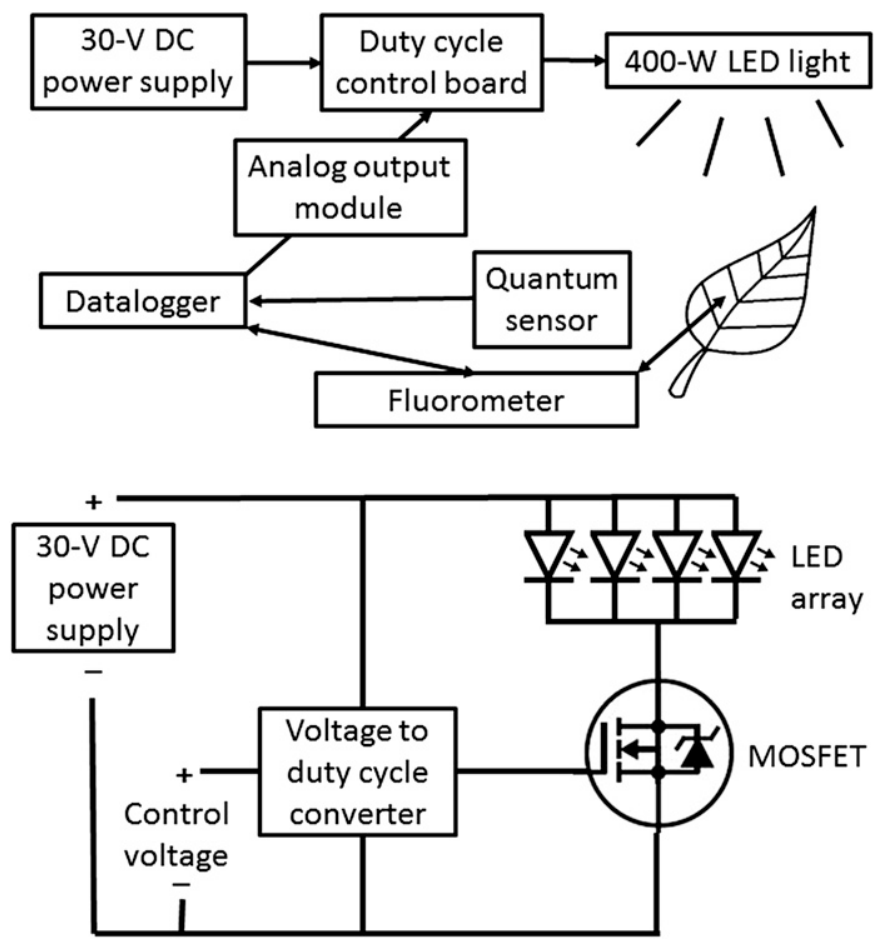

Fig. 1. Diagram of the biofeedback system (top) and a simplified diagram of the duty cycle control board (bottom). A fluorometer is used to measure the quantum yield of photosystem II and the datalogger calculates the electron transport rate from this and the photosynthetic photon flux density (PPFD), measured using a quantum sensor. Based on the measured and target electron transport rate, the datalogger then uses an analog output module to send a voltage signal to the duty cycle control board. The duty cycle control board has a microcontroller that converts the control voltage into a required duty cycle of the light-emitting diodes (LEDs). The control board controls a metaloxide-semiconductor field-effect transistor (MOSFET) that acts like a very fast switch. The MOSFET controls whether the circuit is closed and current can flow through the LEDs. 
measured the maximal fluorescence yield $\left(\mathrm{F}_{\mathrm{m}}\right.$ and $\mathrm{F}_{\mathrm{m}}{ }^{\prime}$, in the dark and light, respectively). The intensity of the saturating light pulse was not monitored, but adjusted as needed to assure that the fluorescence signal truly saturated during $\mathrm{F}_{\mathrm{m}}$ and $\mathrm{F}_{\mathrm{m}}{ }^{\prime}$ measurements. Chlorophyll fluorescence parameters were calculated by the datalogger using the equations developed by Genty et al. (1989) and Bilger and Björkman (1990). The datalogger also collected and stored all data.

Pulse-amplitude modulated chlorophyll fluorometers measure the difference in chlorophyll fluorescence coming from a leaf exposed to actinic light vs. fluorescence induced by actinic light plus a modulated, low-intensity measuring light. These measurements, therefore, depend on a steady-state actinic light. The pulsing nature of the actinic LED lights resulted in high variability in the fluorescence data. To reduce this variability, $F_{\mathrm{s}}$ was estimated as the average of 1000 measurements collected at $20-\mathrm{ms}$ intervals. Note that the variability in $\mathrm{F}_{\mathrm{s}}$ can likely be reduced if the light output from the LEDs were altered by controlling the current going to the LEDs, rather than by changing the duty cycle. We choose to use duty cycle control, because of its ease of implementation.

Maximal fluorescence yield was taken as the highest fluorescence value of 50 measurements collected at $20-\mathrm{ms}$ intervals during a 0.8 - to 1.0 -s saturating pulse. To avoid possible interference from pulsed light with the measurement of $\mathrm{F}_{\mathrm{m}}{ }^{\prime}$, the LEDs were turned off while $\mathrm{F}_{\mathrm{m}}{ }^{\prime}$ was measured. Quantum yield of PSII was calculated as $\Phi_{\text {PSII }}=\left(F_{m}{ }^{\prime}-F_{\mathrm{s}}\right)$ / $\mathrm{F}_{\mathrm{m}}^{\prime}$ (Genty et al., 1989).

At the onset of an experiment, plants were dark adapted overnight, after which dark-adapted chlorophyll fluorescence measurements were collected. A single measurement was used to determine $\mathrm{F}_{\mathrm{o}}$ and maximal chlorophyll fluorescence $\left(\mathrm{F}_{\mathrm{m}}\right)$ was taken as the highest of 50 measurements collected at 20-ms intervals during a 0.8 - to 1.0 -s saturating pulse. The darkadapted quantum efficiency of photochemical energy conversion by PSII $\left(\mathrm{F}_{\mathrm{v}} / \mathrm{F}_{\mathrm{m}}\right)$ was calculated as $\left(\mathrm{F}_{\mathrm{m}}-\mathrm{F}_{\mathrm{o}}\right) / \mathrm{F}_{\mathrm{m}}$ (Genty et al., 1989).

The combination of maximum fluorescence measurements on dark-adapted leaves and under actinic light also allows for the calculation of the apparent rate constant of NPQ $\left[\left(\mathrm{F}_{\mathrm{m}}-\right.\right.$ $\left.\mathrm{F}_{\mathrm{m}}{ }^{\prime}\right) / \mathrm{F}_{\mathrm{m}}{ }^{\prime}$; Bilger and Björkman, 1990]. This provides an estimate of the magnitude of thermal dissipation based on the assumption that NPQ is due solely to thermal energy dissipation (Adams et al., 1999; Baker and Rosenqvist, 2004; Bilger and Björkman, 1990; Demmig-Adams, 1990, 2012).

To estimate the rate of photosynthetic electron transport through PSII, a quantum sensor (LI-190; LI-COR BioSciences, Lincoln, NE) connected to the datalogger was used to measure $P P F D$. This sensor was mounted adjacent to the spot where chlorophyll fluorescence was measured. To estimate ETR, we assumed that photons were equally partitioned between PSI and PSII, and that $84 \%$ of incident PPFD was absorbed by the leaf (Baker, 2008). Thus, ETR is calculated as $\Phi_{\text {PSII }} \times P P F D \times 0.5 \times$ 0.84 . The assumption that the leaves absorb $84 \%$ of incident light is based on data from a wide range of species (Baker, 2008; Björkman and Demmig, 1987). Since plants can alter the ratio of photons absorbed by PSI and PSII through state transitions of the PSII light-harvesting complex (Allen, 2003; Rochaix, 2014), the assumption that electrons are evenly partitioned between the photosystems may not always be correct. However, state transitions mainly occur at very low light levels (Ruban, 2015) and were likely unimportant in this study. Regardless of their potential shortcomings, calculated ETR values provide a useful way of determining relative changes in ETR (Maxwell and Johnson, 2000).

Biofeedback Control. The duty cycle of the LEDs was controlled by the datalogger via the control board based on a specified target ETR. Duty cycle, and thus PPFD, was adjusted based on the deviation of the observed ETR from $\mathrm{ETR}_{\mathrm{T}}$ as follows: new duty cycle $=\left(\mathrm{ETR}_{\mathrm{T}} / \mathrm{ETR}\right) \times$ old duty cycle. Thus, the biofeedback system compensated for low ETR by increasing PPFD and decreased PPFD whenever ETR exceeded $\mathrm{ETR}_{\mathrm{T}}$. An example program of the biofeedback system is available on-line (University of Georgia, 2015).

Plant material. Lettuce 'Green Towers' (for studies with $16 \mathrm{~h}$ constant $\mathrm{ETR}_{\mathrm{T}}$ ) and 'Green Ice' (for stepwise changes in $\mathrm{ETR}_{\mathrm{T}}$ ) was grown from seed in 10-cm containers and used for trials 4 to 6 weeks after germination. These cultivars were used because their leaf morphology makes it easy to use the fluorometer leaf clip. Pothos and sweetpotato 'Marguerite' were propagated from stem cuttings and grown in $15-\mathrm{cm}$ containers. Experiments were conducted 6 to 8 weeks after rooting. Greenhouse temperature averaged $22{ }^{\circ} \mathrm{C}$ and the photoperiod was $\approx 11 \mathrm{~h}$. The daily light integral inside the greenhouse in the 2 weeks before data collection was (mean \pm SD) $8.4 \pm 4.0,9.8 \pm 3.3$, and $9.3 \pm 3.5 \mathrm{~mol} \cdot \mathrm{m}^{-2} \cdot \mathrm{d}^{-1}$ for lettuce, sweetpotato, and pothos, respectively. These three species were selected because of their different light requirements. Pothos is a tropical understory species, well adapted to low light environments, lettuce grows well at intermediate light levels, whereas sweetpotato performs best under high light. All plants were grown in a peat-based soilless substrate (Fafard 2P; Sun Gro Horticulture, Agawam, MA) in a greenhouse on ebb-andflow benches, and irrigated daily with a $15 \mathrm{~N}-2.2 \mathrm{P}-12.5 \mathrm{~K}$ water-soluble fertilizer (15-5-15 Cal-Mag, Everris, Marysville, $\mathrm{OH})$ solution containing $100 \mathrm{mg} \cdot \mathrm{L}^{-1} \mathrm{~N}$.

EXPERIMENTAL SETUP. The LED array was mounted in a growth chamber (E15; Conviron, Winnipeg, MB, Canada), which was set to maintain a constant temperature of $25^{\circ} \mathrm{C}$. During each experiment, a single plant was placed beneath the LED array, the fluorometer leaf clip was attached to the uppermost fully expanded leaf, and the quantum sensor was positioned next to the leaf clip. Sensors were positioned $\approx 55$ $\mathrm{cm}$ below the LED light. Two types of trials were conducted: $\mathrm{ETR}_{\mathrm{T}}$ was maintained at a constant value (70 or 100 $\mu \mathrm{mol} \cdot \mathrm{m}^{-2} \cdot \mathrm{s}^{-1}$ ) for $16 \mathrm{~h}$ or $\mathrm{ETR}_{\mathrm{T}}$ was increased from 0 to a maximum $\mathrm{ETR}_{\mathrm{T}}$ in seven steps, and then decreased again, maintaining each $\mathrm{ETR}_{\mathrm{T}}$ for $1 \mathrm{~h}$. All trials were conducted under ambient $\mathrm{CO}_{2}$ concentrations.

Trials with a constant $\mathrm{ETR}_{\mathrm{T}}$ were conducted with lettuce 'Green Towers', after the plants had acclimated to growth chamber conditions (16-h photoperiod, $25{ }^{\circ} \mathrm{C}$ in the light and $20^{\circ} \mathrm{C}$ in the dark, $P P F D \approx 240 \mu \mathrm{mol} \cdot \mathrm{m}^{-2} \cdot \mathrm{s}^{-1}$ ) for over 2 weeks. During these trials, $\mathrm{F}_{\mathrm{m}}{ }^{\prime}$ was measured every $15 \mathrm{~min}$, whereas $\mathrm{F}_{\mathrm{s}}$ was measured every 5 min. Because changes in $\mathrm{F}_{\mathrm{m}}{ }^{\prime}$ were slow, except for immediately after turning on the LED lights, $\Phi_{\text {PSII }}$ and ETR were calculated assuming that $\mathrm{F}_{\mathrm{m}}{ }^{\prime}$ did not change appreciably in a 15-min period, thereby reducing the frequency of saturating light pulses. Dark-adapted chlorophyll fluorescence measurements were taken hourly for $4 \mathrm{~h}$ before and after the 16-h periods with constant $\mathrm{ETR}_{\mathrm{T}}$.

For stepwise $\mathrm{ETR}_{\mathrm{T}}$ trials, the maximum $\mathrm{ETR}_{\mathrm{T}}$ for each species (pothos, lettuce, and sweetpotato) was chosen based on preliminary studies. Plants were moved from the greenhouse 
into the growth camber the evening before the start of the measurements and dark adapted in the growth chamber overnight. For lettuce, $\mathrm{ETR}_{\mathrm{T}}$ was increased from 0 to $70 \mu \mathrm{mol} \cdot \mathrm{m}^{-2} \cdot \mathrm{s}^{-1}$ in $10-\mu \mathrm{mol} \cdot \mathrm{m}^{-2} \cdot \mathrm{s}^{-1}$ steps, then decreased at the same rate. For sweetpotato, $\mathrm{ETR}_{\mathrm{T}}$ was increased from 0 to $98 \mu \mathrm{mol} \cdot \mathrm{m}^{-2} \cdot \mathrm{s}^{-1}$ in $14-\mu \mathrm{mol} \cdot \mathrm{m}^{-2} \cdot \mathrm{s}^{-1}$ steps and for pothos from 0 to $49 \mu \mathrm{mol} \cdot \mathrm{m}^{-2} \cdot \mathrm{s}^{-1}$ in $7-\mu \mathrm{mol} \cdot \mathrm{m}^{-2} \cdot \mathrm{s}^{-1}$ steps. Each experiment was repeated at least three times with each species. Data presented are from representative runs. Lettuce trials were run using a power supply of $\approx 240 \mathrm{~W}$, which resulted in a maximum $P P F D$ of $\approx 560 \mu \mathrm{mol} \cdot \mathrm{m}^{-2} \cdot \mathrm{s}^{-1}$. A $400-\mathrm{W}$ power supply was used for the pothos and sweetpotato trials, resulting in maximum $P P F D$ of $\approx 940 \mu \mathrm{mol} \cdot \mathrm{m}^{-2} \cdot \mathrm{s}^{-1}$.

Because each $\mathrm{ETR}_{\mathrm{T}}$ was maintained for only $60 \mathrm{~min}, \mathrm{~F}_{\mathrm{s}}$ and $\mathrm{F}_{\mathrm{m}}{ }^{\prime}$ were both measured every $2 \mathrm{~min}$. More frequent measurements were needed than in the trials with constant $\mathrm{ETR}_{\mathrm{T}}$, because of the relative large changes in duty cycle and $P P F D$ needed to reach the various $\mathrm{ETR}_{\mathrm{T}}$ levels, and to assure we collected enough data during each 1 -h period to determine whether ETR was stable. Changes in plant physiological responses over time and relationships among the different physiological variables were analyzed using regression analysis with $P<0.05$ considered to be statistically significant.

\section{Results and Discussion}

Maintaining a STABle ETR. Experiments were conducted during which the biofeedback system was programmed to maintain the ETR of lettuce at 70 or $100 \mu \mathrm{mol} \cdot \mathrm{m}^{-2} \cdot \mathrm{s}^{-1}$ for $16 \mathrm{~h}$. Afterward, the LEDs were turned off and fluorescence data were collected hourly for an additional $4 \mathrm{~h}$ in the dark.

During the trial in which $\mathrm{ETR}_{\mathrm{T}}$ was $70 \mu \mathrm{mol} \cdot \mathrm{m}^{-2} \cdot \mathrm{s}^{-1}, \mathrm{~F}_{\mathrm{v}} / \mathrm{F}_{\mathrm{m}}$ was $\approx 0.82$ in the $4 \mathrm{~h}$ before the lights were turned on (Fig. 2), normal for healthy leaves (Björkman and Demmig, 1987). The first $F_{\mathrm{s}}$ and $\mathrm{F}_{\mathrm{m}}{ }^{\prime}$ data were collected 5 min after the LED lights were turned on (at $232 \mu \mathrm{mol} \cdot \mathrm{m}^{-2} \cdot \mathrm{s}^{-1}$ ) and the observed $\Phi_{\text {PSII }}$ was relatively low $(0.516)$. This low $\Phi_{\text {PSII }}$ shortly after the start of the light period was likely due to the reduction of electron receptors in the electron transport pathway. This results in a closure of PSII reaction centers since the primary PSII electron acceptors are unable to transfer absorbed electrons to the next carrier in the electron transport chain. These reaction centers re-open after light-induced activation of Calvin cycle enzymes allows the reduced nicotinamide adenine dinucleotide phosphate and adenosine triphosphate produced by the light reactions to be used for carbon assimilation (Maxwell and Johnson, 2000). Due to the low $\Phi_{\text {PSII }}$, the initial ETR was $41.5 \mu \mathrm{mol} \cdot \mathrm{m}^{-2} \cdot \mathrm{s}^{-1}$, well below $70 \mu \mathrm{mol} \cdot \mathrm{m}^{-2} \cdot \mathrm{s}^{-1}$. Thus, PPFD was increased by the biofeedback system. After the second $F_{\mathrm{m}}{ }^{\prime}$ measurement, $\Phi_{\text {PSII }}$ increased to 0.643 and ETR was 91.6 $\mu \mathrm{mol} \cdot \mathrm{m}^{-2} \cdot \mathrm{s}^{-1}$. The biofeedback system then downregulated $P P F D$ and was able to maintain a stable ETR $(70.0 \pm 0.8$ $\mu \mathrm{mol} \cdot \mathrm{m}^{-2} \cdot \mathrm{s}^{-1}$, mean $\pm \mathrm{SD}$ ) during the remainder of the $16-\mathrm{h}$ period (Fig. 2). Because $\Phi_{\text {PSII }}$ changed little during this 16-h period $(0.687 \pm 0.006)$, the biofeedback system did not need to make substantial changes in PPFD $\left(243 \pm 2 \mu \mathrm{mol} \cdot \mathrm{m}^{-2} \cdot \mathrm{s}^{-1}\right)$ to



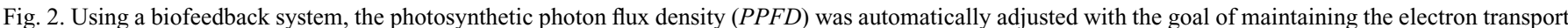
rate $(E T R)$ of lettuce at 70 or $100 \mu \mathrm{mol} \cdot \mathrm{m}^{-2} \cdot \mathrm{s}^{-1}$ (bottom left). (A) The quantum yield of photosystem II ( $\left.\Phi_{\text {PSII }}\right)$ was measured and used to calculate $(\mathbf{B})$ the electron transport rate. At a target ETR of $100 \mu \mathrm{mol} \cdot \mathrm{m}^{-2} \cdot \mathrm{s}^{-1}, \Phi_{\text {PSII }}$ gradually declined, whereas (C) nonphotochemical quenching increased. As a result, (D) $P P F D$ had to be gradually increased throughout the 16 -h light period to maintain a target ETR of $100 \mu \mathrm{mol} \cdot \mathrm{m}^{-2} \cdot \mathrm{s}^{-1}$. This was not the case with a target ETR of $70 \mu \mathrm{mol} \cdot \mathrm{m}^{-2} \cdot \mathrm{s}^{-1}$, where $\Phi_{\text {PSII }}$ and nonphotochemical quenching were stable throughout the 16-h light period. After $16 \mathrm{~h}$, the light was turned off and $\Phi_{\text {PSII }}$ rapidly recovered. 
maintain ETR close to $70 \mu \mathrm{mol} \cdot \mathrm{m}^{-2} \cdot \mathrm{s}^{-1}$. NPQ during this period remained steady at $0.383 \pm$ 0.007 . Following the $16 \mathrm{~h}$ light period $\mathrm{F}_{\mathrm{v}} / \mathrm{F}_{\mathrm{m}}$ was $\approx 0.83$, indicating that the fluorescence measurements did not cause damage to PSII (Fig. 2). We subsequently have seen reductions in $\mathrm{F}_{\mathrm{v}} / \mathrm{F}_{\mathrm{m}}$ of lettuce after $16 \mathrm{~h}$ of more frequent $\mathrm{F}_{\mathrm{m}}{ }^{\prime}$ measurements (every 5 min or less), indicating that these measurements can induce photoinhinbition. This appears to be the result of the frequent application of saturating light pulses needed for the measurement of $\mathrm{F}_{\mathrm{m}}{ }^{\prime}$.

With an $\mathrm{ETR}_{\mathrm{T}}$ of $100 \mu \mathrm{mol} \cdot \mathrm{m}^{-2} \cdot \mathrm{s}^{-1}$, the initial $\Phi_{\text {PSII }}$ was low and NPQ was high (Fig. 2 ), similar to the response observed at an $\mathrm{ETR}_{\mathrm{T}}$ of $70 \mu \mathrm{mol} \cdot \mathrm{m}^{-2} \cdot \mathrm{s}^{-1}$. Once again, the low $\Phi_{\text {PSII }}$ resulted in a low ETR and a high initial PPFD. However, after the second $\mathrm{F}_{\mathrm{m}}{ }^{\prime}$ measurement, the system was able to adjust the $P P F D$ and maintain the ETR close to 100 $\mu \mathrm{mol} \cdot \mathrm{m}^{-2} \cdot \mathrm{s}^{-1}\left(100.0 \pm 1.7 \mu \mathrm{mol} \cdot \mathrm{m}^{-2} \cdot \mathrm{s}^{-1}\right)$ for the remainder of the $16-\mathrm{h}$ period. To maintain this ETR, the biofeedback system had to gradually, and linearly, increase the $P P F D$, from 389 to $409 \mu \mathrm{mol} \cdot \mathrm{m}^{-2} \cdot \mathrm{s}^{-1}(r=0.68, P<$ 0.0001). This increase in $P P F D$ was needed, because $\Phi_{\text {PSII }}$ decreased gradually over time, from 0.612 to $0.582(r=-0.72, P<0.0001)$, whereas NPQ increased $(r=0.90, P<$ $0.0001)$. The decrease in $\Phi_{\text {PSII }}$ was negatively correlated with the increase in NPQ $(r=-0.73, P<0.0001)$. This increase in NPQ was likely due to the upregulation of the xanthophyll cycle: lumen acidification triggers the de-epoxidation of violaxanthin to form antheraxanthin and zeaxanthin, which leads to the dissipation of excess absorbed light energy as heat (DemmigAdams et al., 2012; Horton, 2012; Rochaix, 2014). In the dark period following the light cycle, $\mathrm{F}_{\mathrm{v}} / \mathrm{F}_{\mathrm{m}}$ was $\approx 0.815$. This high $\mathrm{F}_{\mathrm{v}} / \mathrm{F}_{\mathrm{m}}$ indicates that there was no damage to PSII (Björkman and Demmig, 1987).

Controlling ETR in a stepwise pattern. A series of experiments was conducted to test the ability of the biofeedback system to effectively alter and control ETR over time. In these studies, the system was programmed to change $\mathrm{ETR}_{\mathrm{T}}$ once every hour. The ETR $\mathrm{E}_{\mathrm{T}}$ was gradually increased and then decreased in a stepwise pattern over the course of $15 \mathrm{~h}$. Lettuce and sweetpotato showed similar responses in these studies. Control of ETR was good when ETR $_{\mathrm{T}}$ was low, but the maximum ETR that could be maintained was $\approx 60$ and $84 \mu \mathrm{mol} \cdot \mathrm{m}^{-2} \cdot \mathrm{s}^{-1}$ for lettuce and sweetpotato, respectively (Fig. 3). This lower maximum ETR for lettuce was partly due to the lower maximum $P P F D$ levels during the lettuce trials (maximum $P P F D$ of $\approx 560 \mu \mathrm{mol} \cdot \mathrm{m}^{-2} \cdot \mathrm{s}^{-1}$ ) than during the sweetpotato trials (maximum $P P F D$ of $\approx 940 \mu \mathrm{mol} \cdot \mathrm{m}^{-2} \cdot \mathrm{s}^{-1}$ ) This difference in maximum $P P F D$ resulted from the use of different power supplies in the lettuce and sweetpotato studies. The ETR of pothos was controlled over the entire range tested, but ETR became increasingly more variable at higher $\mathrm{ETR}_{\mathrm{T}}$ levels. To a lesser extent, this was true for lettuce and sweetpotato as well, and this response is similar to that seen when the ETR $\mathrm{T}_{\mathrm{T}}$ of lettuce was maintained steady for $16 \mathrm{~h}$; ETR was more variable with an $\mathrm{ETR}_{\mathrm{T}}$ of 100 than with an ETR $\mathrm{T}$ of $70 \mu \mathrm{mol} \cdot \mathrm{m}^{-2} \cdot \mathrm{s}^{-1}$ (Fig. 2).

As expected, $P P F D$ had to be gradually increased to achieve higher ETR levels. As ETR $_{\mathrm{T}}$ was gradually increased, $P P F D$ even needed to be increased during the 1-h periods in which $\mathrm{ETR}_{\mathrm{T}}$ was unchanged to maintain that steady ETR level. For example, to maintain a lettuce ETR of $30 \mu \mathrm{mol} \cdot \mathrm{m}^{-2} \cdot \mathrm{s}^{-1}, P P F D$ needed to be increased from 135 to $155 \mu \mathrm{mol} \cdot \mathrm{m}^{-2} \cdot \mathrm{s}^{-1}$. This response was most notable in sweetpotato and lettuce and was due to a decrease in $\Phi_{\text {PSII }}$ during this time (Fig. 4). Conversely, as $\mathrm{ETR}_{\mathrm{T}}$ was gradually decreased (8-15 hours), no large changes in PPFD were needed to maintain a stable ETR. All three plant species required a higher $P P F D$ to achieve the same $\mathrm{ETR}_{\mathrm{T}}$ during the latter half of these studies, when $\mathrm{ETR}_{\mathrm{T}}$ was gradually decreased, than during the first half when ETR $_{T}$ was increased (Fig. 5). For example, during the period of increasing ETR $_{\mathrm{T}}$ with lettuce, the average $P P F D$ required to maintain an ETR of $30 \mu \mathrm{mol} \cdot \mathrm{m}^{-2} \cdot \mathrm{s}^{-1}$ was $145 \mu \mathrm{mol} \cdot \mathrm{m}^{-2} \cdot \mathrm{s}^{-1}$, as compared with $265 \mu \mathrm{mol} \cdot \mathrm{m}^{-2} \cdot \mathrm{s}^{-1}$ during the period that $\mathrm{ETR}_{\mathrm{T}}$ was decreased (Figs. 3 and 5). This is a direct consequence of the higher $\Phi_{\mathrm{PSII}}$ during the period of increasing $\mathrm{ETR}_{\mathrm{T}}$ than during decreasing ETR $_{\mathrm{T}}$.

There was a large decrease in $\Phi_{\text {PSII }}$ during the initial $8 \mathrm{~h}$ of these trials, as ETR $\mathrm{T}_{\mathrm{T}}$ and $P P F D$ were increased. This was most pronounced in pothos and sweetpotato, possibly because these 


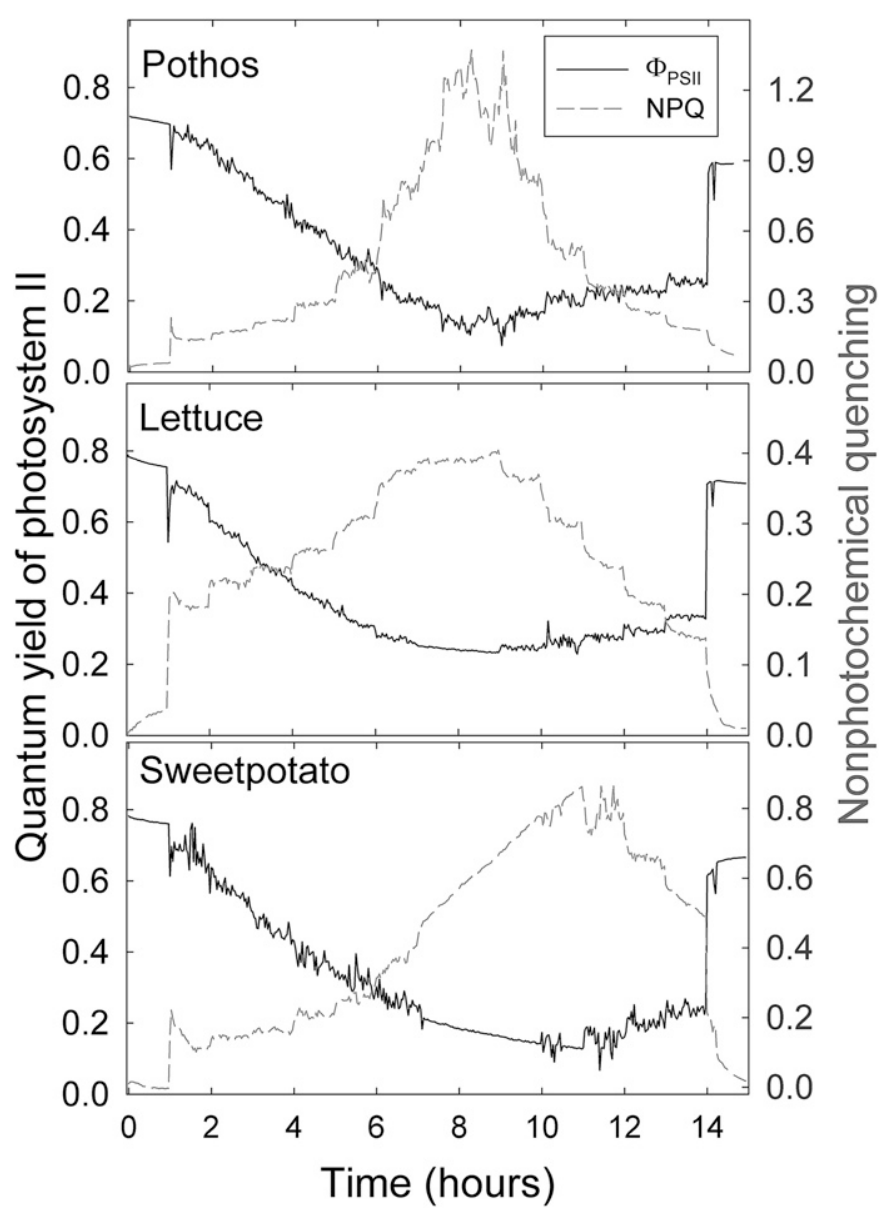

Fig. 4. The quantum yield of photosystem II $\left(\Phi_{\mathrm{PSII}}\right)$ and nonphotochemical quenching (NPQ) of pothos, lettuce, and sweetpotato over a $15-\mathrm{h}$ period during which the target electron transport rate was increased and then decreased in a stepwise manner (Fig. 3).

plants were exposed to higher light levels than lettuce. In all three species, this decrease in $\Phi_{\text {PSII }}$ was associated with an increase in NPQ (Fig. 4), a typical response to increasing PPFD (e.g., Demmig-Adams et al., 1996). There was also a strong relationship between decreasing $\Phi_{\text {PSII }}$ and increasing NPQ during the period that $\mathrm{ETR}_{\mathrm{T}}$ was increased for all species (Fig. 6), as was recently also found for Arabidopsis thaliana (Ware et al., 2015). The relationship between NPQ and $\Phi_{\text {PSII }}$ of both lettuce and pothos differed during the period of increasing $\mathrm{ETR}_{\mathrm{T}}$, as compared with the period of decreasing $\mathrm{ETR}_{\mathrm{T}}($ Fig. 6). As ETR $\mathrm{E}_{\mathrm{T}}$ was decreased, NPQ of lettuce and pothos also decreased rapidly. However, with sweetpotato, the pattern of the change in NPQ differed, and NPQ increased throughout the first $11 \mathrm{~h}$ of the trial. This different response of sweetpotato is consistent with the notion that the regulation of short- and longterm changes of $\Phi_{\text {PSII }}$ and xanthophyll cycle activity is species specific (Demmig-Adams et al., 2012).

The decrease in NPQ of lettuce and pothos during the latter half of these trials resulted in only small increases in $\Phi_{\text {PSII }}$ (Figs. 4 and 6). The same level of NPQ during the period of decreasing $\mathrm{ETR}_{\mathrm{T}}$ resulted in lower $\Phi_{\mathrm{PSII}}$ than during the initial $8 \mathrm{~h}$ of increasing $\mathrm{ETR}_{\mathrm{T}}$. This effect was less pronounced in sweetpotato, which showed a slower downregulation of NPQ as $\mathrm{ETR}_{\mathrm{T}}$ was decreased. The relationship between NPQ and $\Phi_{\mathrm{PSII}}$

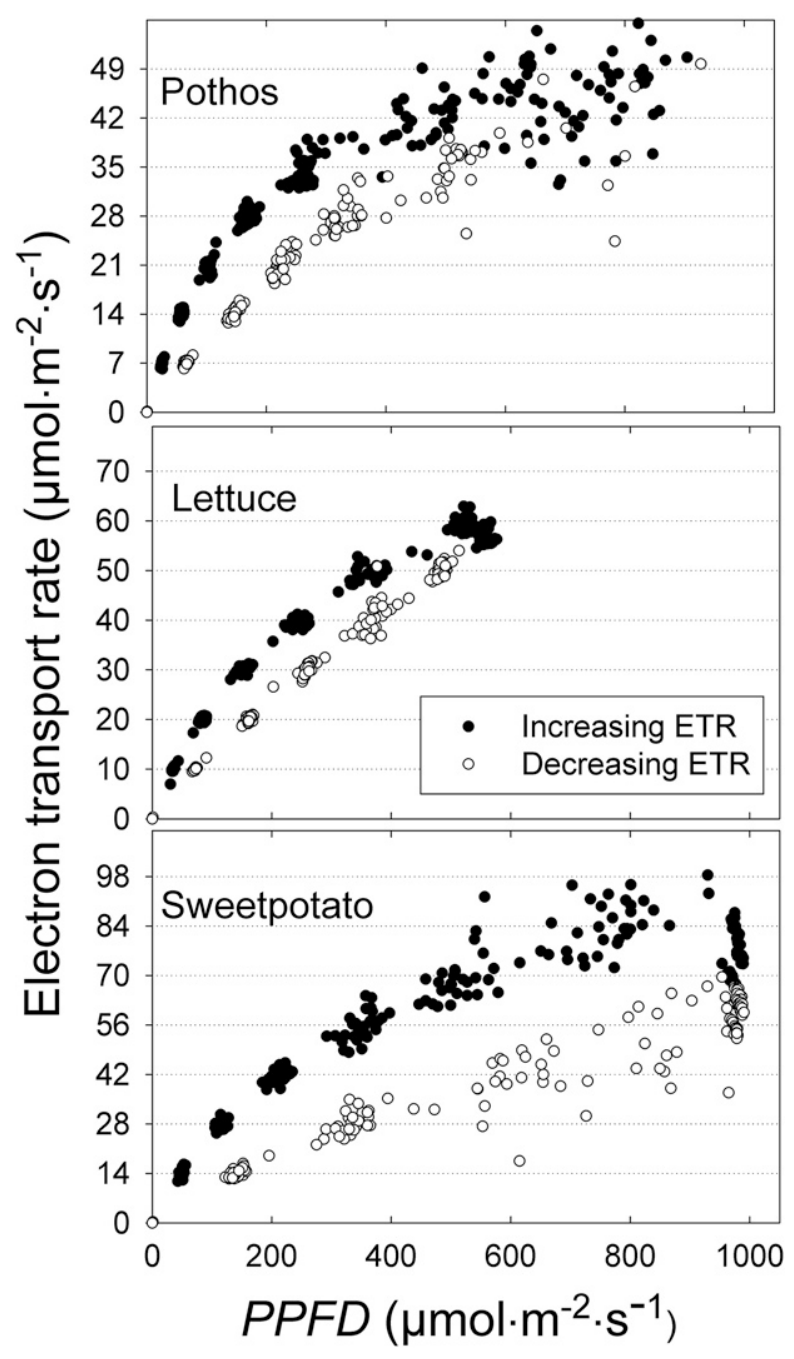

Fig. 5. The electron transport rate (ETR) of lettuce, sweetpotato, and pothos as a function of photosynthetic photon flux density (PPFD). The target electron transport rate $\left(\mathrm{ETR}_{\mathrm{T}}\right.$, dashed horizontal lines) was increased during the first $8 \mathrm{~h}$ and then decreased again (Fig. 3). Higher PPFD was required during the phase of decreasing $\mathrm{ETR}_{\mathrm{T}}$ than during the period of increasing $\mathrm{ETR}_{\mathrm{T}}$ to maintain the same ETR.

of sweetpotato was similar during the periods of increasing and decreasing ETR $_{\mathrm{T}}$.

There was a slow and gradual decline in $\mathrm{F}_{\mathrm{v}} / \mathrm{F}_{\mathrm{m}}$ during the initial $1 \mathrm{~h}$ of darkness, regardless of species (Fig. 3). This indicates that measuring chlorophyll fluorescence every $2 \mathrm{~min}$ had a significant impact on the physiology of the measured leaves. This was also reflected in a slow, gradual increase in NPQ of lettuce and pothos during this period. When the lights were turned off again after $14 \mathrm{~h}, \mathrm{~F}_{\mathrm{v}} / \mathrm{F}_{\mathrm{m}}$ did not recover to the initial $\mathrm{F}_{\mathrm{v}} / \mathrm{F}_{\mathrm{m}}$, and was well below the 0.82 that is considered typical for healthy leaves (Björkman and Demmig, 1987). This lasting reduction in $\mathrm{F}_{\mathrm{v}} / \mathrm{F}_{\mathrm{m}}$ was not due to NPQ, which did decrease during the final dark period to levels close to those at the start of these experiments (Fig. 4).

The low $\mathrm{F}_{\mathrm{v}} / \mathrm{F}_{\mathrm{m}}$ at the end of these trials is consistent with the poor recovery of $\Phi_{\mathrm{PSI}}$ as $\mathrm{ETR}_{\mathrm{T}}$ and $P P F D$ were gradually decreased during the latter part of these studies. Long-lasting depressions in $\Phi_{\text {PSII }}$ can be due to elevated levels of xanthophylls cycle pigments; prolonged light stress can promote the accumulation and retention of zeaxanthin (Demmig-Adams 


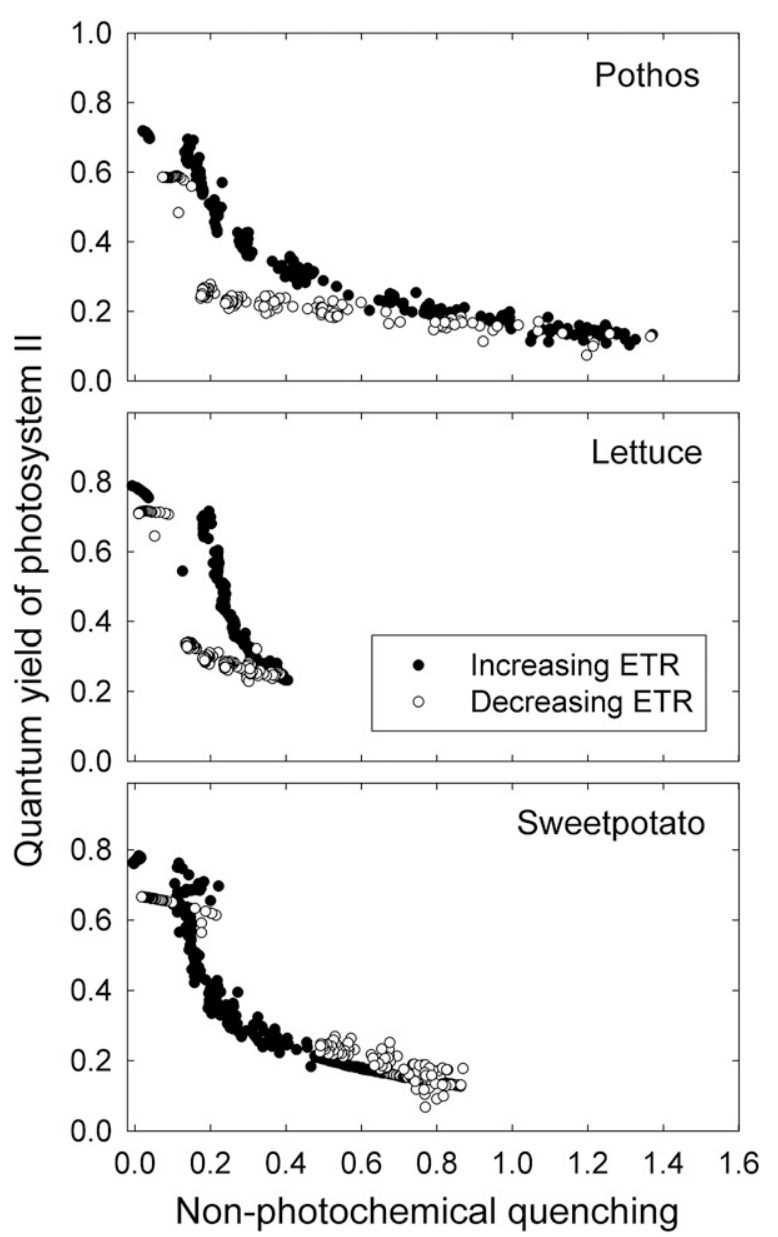

Fig. 6. The quantum yield of photosystem II $\left(\Phi_{\text {PSII }}\right)$ as a function of nonphotochemical quenching (NPQ) of lettuce, sweetpotato, and pothos. The target electron transport rate (ETR) was altered in a stepwise pattern over a 15-h period, resulting in a wide range of photosynthetic photon flux densities $(P P F D)$ (Fig. 3). As the target ETR was increased during the first 8-h period, NPQ was upregulated and $\Phi_{\text {PSII }}$ decreased. As the target ETR was decreased during the last $7 \mathrm{~h}$, NPQ of lettuce and pothos decreased greatly, with only a small increase in $\Phi_{\text {PSII }}$. This suggests that $\Phi_{\text {PSII }}$ of lettuce and pothos was limited by a process other than NPQ, likely photoinhibition.

and Adams, 2006; Demmig-Adams et al., 2012; Horton, 2012; Ruban, 2015). An accumulation of zeaxanthin should be evident from prolonged high NPQ levels (i.e., sweetpotato), which was not seen in lettuce or pothos. The different relationship between NPQ and $\Phi_{\text {PSII }}$ of lettuce and pothos during the periods of increasing and decreasing $\mathrm{ETR}_{\mathrm{T}}$ indicates that the low $\Phi_{\text {PSII }}$ during the latter half of these studies was not caused by high NPQ. Instead, the low $\Phi_{\text {PSII }}$ of lettuce and pothos during the period of decreasing $\mathrm{ETR}_{\mathrm{T}}$ was likely due to photoinhibition. High light levels can induce damage to the reaction centers, making them nonfunctional and decrease $\Phi_{\text {PSII }}$ and thus ETR (Ruban, 2015). Photosystem II is particularly sensitive to photoinhibition, which typically results in degradation of the D1 protein, an integral core PSII reaction center protein (Horton, 2012; Horton and Ruban, 2005; Rochaix, 2014; Ruban, 2015). Since the repair of D1 proteins can take several hours (Ohad et al., 1984), photoinhibition can reduce $\Phi_{\text {PSII }}$ and ETR for prolonged periods (Demmig-Adams et al., 2012; Horton, 2012; Ruban, 2015). A decrease in $\Phi_{\text {PSII }}$ as a result of upregulation of NPQ is easily distinguished from photoinhibition using chlorophyll fluorescence measurements, since upregulation of NPQ is observed as a decrease in $\mathrm{F}_{\mathrm{m}}{ }^{\prime}$, but a decline in $\Phi_{\text {PSII }}$ can be due to a decrease in $F_{m}{ }^{\prime}$ or an increase in $\mathrm{F}_{\mathrm{s}}$. The low $\Phi_{\text {PSII }}$ observed in the trials with pothos and lettuce was associated with a prolonged high level of $\mathrm{F}_{\mathrm{s}}$ even while $P P F D$ was decreasing (results not shown), which indicates that photoinhibition was the cause. This is consistent with the findings by Ruban (2015), who showed that photoinhibition can be determined from $\mathrm{F}_{\mathrm{s}}$ measurements. Recently, we have determined that photoinhibition in lettuce can result from frequent $\mathrm{F}_{\mathrm{m}}{ }^{\prime}$ measurements: measuring $\mathrm{F}_{\mathrm{m}}{ }^{\prime}$ at intervals of $5 \mathrm{~min}$ or shorter induces an increase in $\mathrm{F}_{\mathrm{s}}$, whereas measurement intervals of $15 \mathrm{~min}$ or longer do not (unpublished results). Apparently, exposing leaves to the very high PPFD of a saturating light pulse too frequently induces photoinhibition, even if the saturating light is applied for as little as $1 \mathrm{~s}$ every 5 min. $F_{m}{ }^{\prime}$ generally does not change rapidly under conditions with relative stable $P P F D$, as is evident from the slow changes in NPQ when ETR is maintained at a stable level for prolonged periods (Fig. 2). Under such conditions, it is possible to measure $\mathrm{F}_{\mathrm{s}}$ more frequently and to calculate $\Phi_{\mathrm{PSII}}$ using less frequent $\mathrm{F}_{\mathrm{m}}{ }^{\prime}$ measurements.

Prospects for optimizing Lighting. The goal of the reported work was to develop a biofeedback system that can monitor $\Phi_{\text {PSII }}$ and calculate ETR, and then use that information to adjust the $P P F D$ to maintain a specific ETR. Future work will focus on ways to use this system to optimize crop production. This work will need to include both a plant physiology and an economic component. In principle, the biofeedback system can be used not only to control ETR, but also to maintain a specific $\Phi_{\text {PSII }}$ or, perhaps, NPQ. To achieve optimal efficiency, it may be necessary to develop algorithms that take into account ETR, $\Phi_{\text {PSII }}$, and NPQ. From an economic perspective, it may be necessary to take the cost of electricity into account as well, since the economically optimal light level will be higher when electricity prices are lower. In the case of variable electricity prices, growers may be able to aim for higher ETRs during times that the cost of electricity is low. To automate such an approach, real-time electricity prices would need to be incorporated into the control algorithm. This approach is not limited to vertical farms, but can be used in greenhouses as well, applying supplemental light only as needed. This may be especially beneficial under conditions with fluctuating PPFD from sun light (e.g., in greenhouses), which results in fluctuating $\Phi_{\text {PSII }}$ (Janka et al., 2015) and ETR. The biofeedback system can automatically adjust the supplemental light levels to assure that ETR is maintained at or above a specific minimum threshold. Alternatively, the supplemental light could be provided only when $\Phi_{\text {PSII }}$ is relatively high and light can be used efficiently.

\section{Conclusions}

Chlorophyll fluorescence measurements are a powerful tool for monitoring crop performance. The ETR of lettuce, sweetpotato, and pothos was effectively controlled based on realtime measurements of $\Phi_{\text {PSII }}$ and PPFD. The biofeedback system successfully maintained a wide range of ETR values in different species. High ETR was associated with lower $\Phi_{\text {PSII }}$, so the challenge for achieving increased efficiency of conversion of electrical energy into electron transport will be to find ways to minimize NPQ and photoinhibition. Chlorophyll 
fluorescence measurements can be used not only to monitor and control $\Phi_{\text {PSII }}$ and ETR, but also to detect reasons for a low $\Phi_{\text {PSII }}$, distinguishing between NPQ and photoinhibition based on changes in $\mathrm{F}_{\mathrm{m}}{ }^{\prime}$ and $\mathrm{F}_{\mathrm{s}}$. The biofeedback system has potential applications in controlled environment agriculture, as well as basic plant physiology studies, where the system can be used to maintain specific levels of physiological activity. Care must be taken to not measure $\mathrm{F}_{\mathrm{m}}{ }^{\prime}$ too frequently, since these measurements can induce physiological damage, lowering $\Phi_{\text {PSII }}$ and ETR.

\section{Literature Cited}

Adams, W.W., III, B. Demmig-Adams, B.A. Logan, D.H. Barker, and C.B. Osmond. 1999. Rapid changes in xanthophyll cycle-dependent energy dissipation and photosystem II efficiency in two vines, Stephania japonica and Smilax australis, growing in the understory of an open Eucalyptus forest. Plant Cell Environ. 22:125-136.

Allen, J.F. 2003. State transitions-a question of balance. Science 299:1530-1532.

Baker, N.R. and E. Rosenqvist. 2004. Applications of chlorophyll fluorescence can improve crop production strategies: An examination of future possibilities. J. Expt. Bot. 55:1607-1621.

Baker, N.R. 2008. Chlorophyll fluorescence: A probe of photosynthesis in vivo. Annu. Rev. Plant Biol. 59:89-113.

Bilger, W. and O. Björkman. 1990. Role of the xanthophyll cycle in photoprotection elucidated by measurements of light-induced absorbance changes, fluorescence and photosynthesis in leaves of Hedera canariensis. Photosyn. Res. 25:173-185.

Björkman, O. and B. Demmig. 1987. Photon yield of $\mathrm{O}_{2}$ evolution and chlorophyll fluorescence at $77 \mathrm{k}$ among vascular plants of diverse origins. Planta 170:489-504.

Bourget, C.M. 2008. An introduction to light-emitting diodes. HortScience 43:1944-1946.

Demmig-Adams, B. 1990. Carotenoids and photoprotection in plants: A role for the xanthophyll zeaxanthin. Biochim. Biophys. Acta 1020:1-24.

Demmig-Adams, B., W.W. Adams, III, D.H. Barker, B.A. Logan, D.R. Bowling, and A.S. Verhoeven. 1996. Using chlorophyll fluorescence to assess the fraction of absorbed light allocated to thermal dissipation of excess excitation. Physiol. Plant. 98:253-264.

Demmig-Adams, B. and W.W. Adams, III. 2006. Photoprotection in an ecological context: The remarkable complexity of thermal energy dissipation. New Phytol. 172:11-21.

Demmig-Adams, B., C.M. Cohu, W.W. Muller, and W.W. Adams. 2012. Modulation of photosynthetic energy conversion in nature: From seconds to seasons. Photosyn. Res. 113:75-78.

Despommier, D. 2010. The vertical farm: Feeding the world in the $21 \mathrm{st}$ century. St. Martin's, New York, NY.

Despommier, D. 2013. Farming up the city: The rise of urban vertical farms. Trends Biotechnol. 31:388-399.

Dietz, K. 2015. Efficient high light acclimation involves rapid processes at multiple mechanistic levels. J. Expt. Bot. 66:2401-2414.

Genty, B., J. Briantais, and N.R. Baker. 1989. The relationship between the quantum yield of photosynthetic electron transport and quenching of chlorophyll fluorescence. Biochim. Biophys. Acta 990:87-92.

Germer, J., J. Sauerborn, F. Asch, J. de Boer, J. Schreiber, G. Weber, and J. Müller. 2011. Skyfarming an ecological innovation to enhance global food security. J. Consumer Protection Food Safety 6:237-251.
Goto, E. 2012. Plant production in a closed plant factory with artificial lighting. Acta Hort. 956:37-49.

Horton, P. 2012. Optimization of light harvesting and photoprotection: Molecular mechanisms and physiological consequences. Philos. Trans. R. Soc. Lond. B Biol. Sci. 367:3455-3465.

Horton, P. and A. Ruban. 2005. Molecular design of the photosystem II light-harvesting antenna: photosynthesis and photoprotection. J. Expt. Bot. 56:365-373.

Janka, E., O. Körner, E. Rosenqvist, and C.-O. Ottosen. 2015. Using the quantum yields of photosystem II and the rate of net photosynthesis to monitor high irradiance and temperature stress in chrysanthemum (Dendranthema grandiflora). Plant Physiol. Biochem. 90:14-22.

Liu, W. 2012. Light environment management for artificial protected horticulture. Agrotechnology 1:101.

Maxwell, K. and G.N. Johnson. 2000. Chlorophyll fluorescence-a practical guide. J. Expt. Bot. 51:659-668.

Mok, H.F., V.G. Williamson, J.R. Grove, K. Burry, S.F. Barker, and A.J. Hamilton. 2014. Strawberry fields forever? Urban agriculture in developed countries: A review. Agron. Sustain. Dev. 34:21-43. Morrow, R.C. 2008. LED lighting in horticulture. HortScience 43:1947-1950.

Nelson, J.A. and B. Bugbee. 2014. Economic analysis of greenhouse lighting: Light emitting diodes vs. high intensity discharge fixtures. PLoS One 9:e99010.

Ohad, I., D.J. Kyle, and C.J. Arntzen. 1984. Membrane-protein damage and repair: Removal and replacement of inactivated 32-kilodalton polypeptides in chloroplast membranes. J. Cell Biol. 99:481-485.

Ouzounis, T., E. Rosenqvist, and C.-O. Ottosen. 2015. Spectral effects of artificial; light on plant physiology and secondary metabolism: A review. HortScience 50:1128-1135.

Pocock, T. 2015. Light-emitting diodes and the modulation of specialty crops: Light sensing and signaling networks in plants. HortScience 50:1281-1284.

Rochaix, J. 2014. Regulation and dynamics of the light-harvesting system. Annu. Rev. Plant Biol. 65:287-309.

Ruban, A.V. 2015. Evolution under the sun: Optimizing light harvesting in photosynthesis. J. Expt. Bot. 66:7-23.

Thomaier, S., K. Specht, D. Henckel, A. Dierich, R. Siebert, U.B. Freisinger, and M. Sawicka. 2015. Farming in and on buildings: Present practice and specific novelties of zero-acreage farming (ZFarming). Renew. Agr. Food Syst. 30:43-54.

University of Georgia. 2015. Biofeedback control of supplementary lighting based on chlorophyll fluorescence. 23 Dec. 2015. <http:// hortphys.uga.edu/Biofeedback.html $>$.

Ware, M.A., E. Belgio, and A.V. Ruban. 2015. Photoprotective capacity of non-photochemical quenching in plants acclimated to different light intensities. Photosyn. Res. 10.1007/s11120-015-0102-4.

Watanabe, H. 2011. Light-controlled plant cultivation system in Japan - Development of a vegetable factory using LEDs as a light source for plants. Acta Hort. 907:37-44.

Yeh, N. and J. Chung. 2009. High-brightness LEDs - energy efficient lighting sources and their potential in indoor plant cultivation. Renew. Sustain. Energy Rev. 13:2175-2180.

Zeidler, C., D. Schubert, and V. Vrakking. 2013. Feasibility study: Vertical Farm EDEN. German Aerospace Ctr., Inst. Space Systems, Dept. System Analyse Space Segment (SARA), Bremen, Germany. 